\section{Project Helps Constrain Continental Dynamics and Seismic Hazards}

\section{PAGES 383, 387}

The Global Strain Rate Map project II-8, initiated in 1998 by the International Lithosphere Program (ILP), provides constraints for understanding continental dynamics and for quantifying seismic hazards in general. To date, the Global Strain Rate Map (GSRM) model is a numerical velocity gradient tensor field solution (i.e., spatial variations of horizontal strain rate tensor components and rotation rates) for the entire Earth surface [Kreemer et al.,2003].

The global model consists of 25 rigid spherical plates and $\sim 25,0000.6^{\circ} \times 0.5^{\circ}$ deformable grid areas within the diffuse plate boundary zones which lie between these plates (e.g., western North America, central Asia, the Alpine-Himalaya belt). This model provides an estimate of the horizontal strain rates, rotation rates, and velocity fields for the diffuse plate boundary zones as well as an estimate of the motions of the spherical caps.

This is one of the first successful models of its kind that includes the kinematics of plate boundary zones in the description of global plate kinematics. The vast majority of the data used to obtain this model come from horizontal velocity measurements obtained using Global Positioning System (GPS).

The latest model (GSRM v.1.2) includes 5170 velocities for 4214 sites worldwide (Figure 1). Most geodetic velocities are measured within plate boundary zones. The observed velocities are obtained from 86 different studies; most are published, but also included are online data made available by the Southern California Earthquake Center (SCEC) and the U.S. Geological Survey (USGS). A full list of references that provided data to define the model can be found at the GSRM home page, http://www.world-strain-map.org.

One of the studies fundamental in defining spherical cap motions in the GSRM is the GPS Velocity Model (GPSVEL v.1.0) solution, which is based on an analysis of mainly International GPS Service (IGS) data.Weekly station coordinate estimates from the seven global IGS analycenters are rigorously combined using a freenetwork approach [Davies and Blewitt,2000].

\section{Interactive Web Site for GSRM}

The GSRM home page has an introduction where one can access information on the methodology, data and references, model results, and acknowledgments. The model page provides links to an interactive map tool of the GSRM model that is useful for education and research purposes.

By W. E. Holt, C. KreEmer, A. J. Haines, L. Estey, C. MEertens, G. BlewitT, And D. Lavallée sis centers and three regional associate analysis
This map tool, housed and developed at UNAVCO and known as the Jules Verne Voyager (JVV), consists of a powerful cluster of map processing computers and a halfterabyte of disk storage. The JVV generates maps on demand using the Generic Mapping Tools (GMT) on the GSRM Web site computer. The GSRM special edition of JVV (http://jules.unavco.org/Voyager/ILP_GSRM) allows users to interact with maps, creating zoom maps of the GSRM model of any area and scale.

The JVV map engine then creates maps "on the fly" using GMT-based map scripts. The products of the maps can be downloaded, in either postscript or gif format, for later use (e.g., Figure 2).

Whereas publications provide only a selected and static view of model results, the interactive map allows users to view the define the GSRM model (geologic, seismic, and geodetic), the tectonic plate and finite element plate-boundary zone model itself, and a range of model output views such as strain rate principal axes, observed and model-predicted focal mechanisms (based on the model output strain tensor), and plate boundaries.

Users can zoom into any region of the Earth, examine the model and results in detail, and make comparisons with other data. The geodetic compilation allows users to select from some 26 frames of reference, allowing a visual representation of "absolute" plate motion (in a no-net-rotation reference frame) and relative motion along all of the world's plate boundaries. complete set of input observations used to

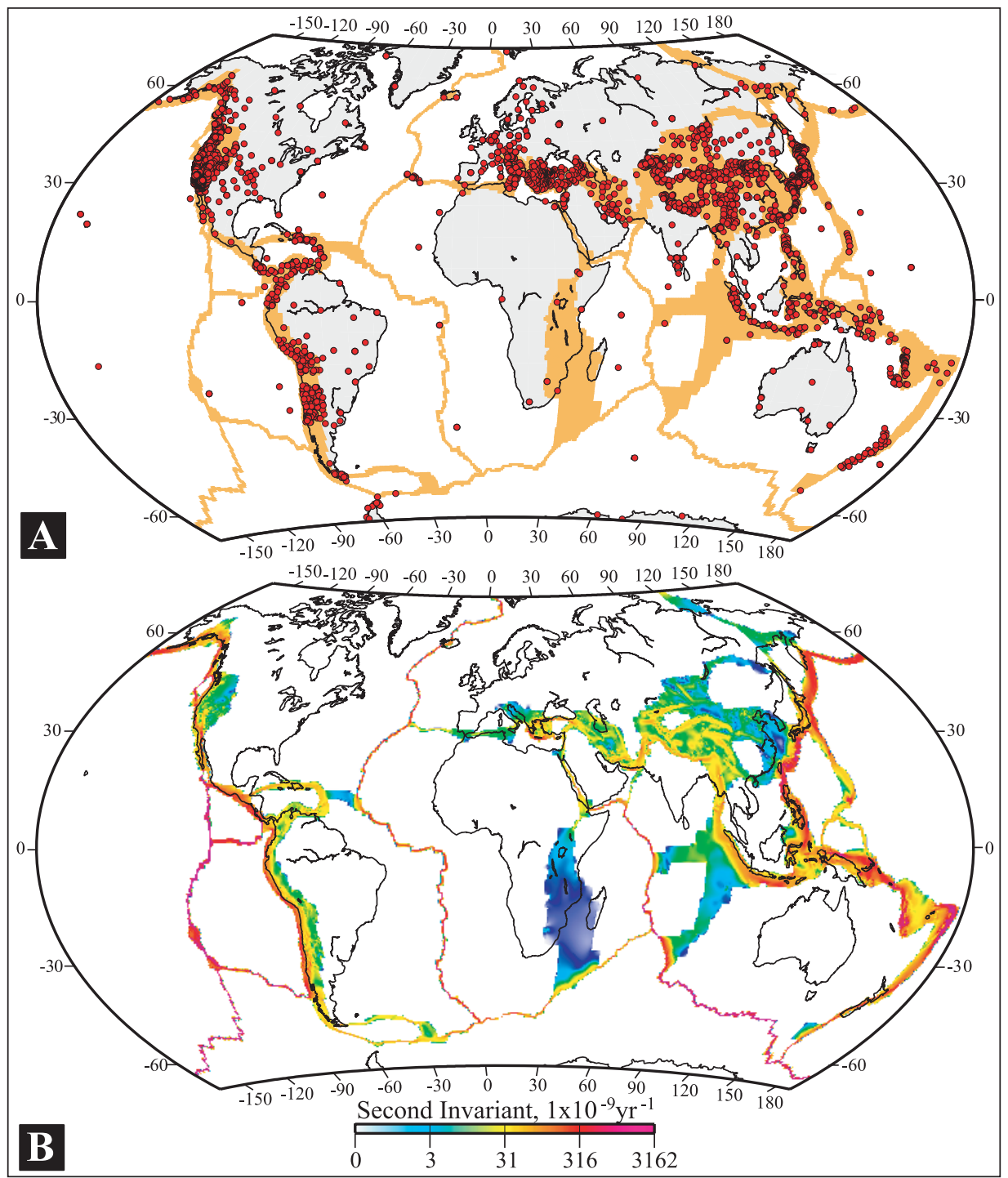

Fig. 1. (a) Locations of all geodetic velocities used to constrain the most recent Global Strain Rate Map. Shown in orange is an outline of the areas that are assumed to be plate boundary zones. These areas are composed of $0.5^{\circ} \times 0.6^{\circ}$ grid elements within which strain rate model estimates are obtained. All other areas are assumed to be part of rigid plates/blocks. (b) Contour plot of the interpolated second invariant of model strain rate tensor obtained through an interpolation of the geodetic velocities. 
Eos, Vol. 86, No. 41, 11 October 2005

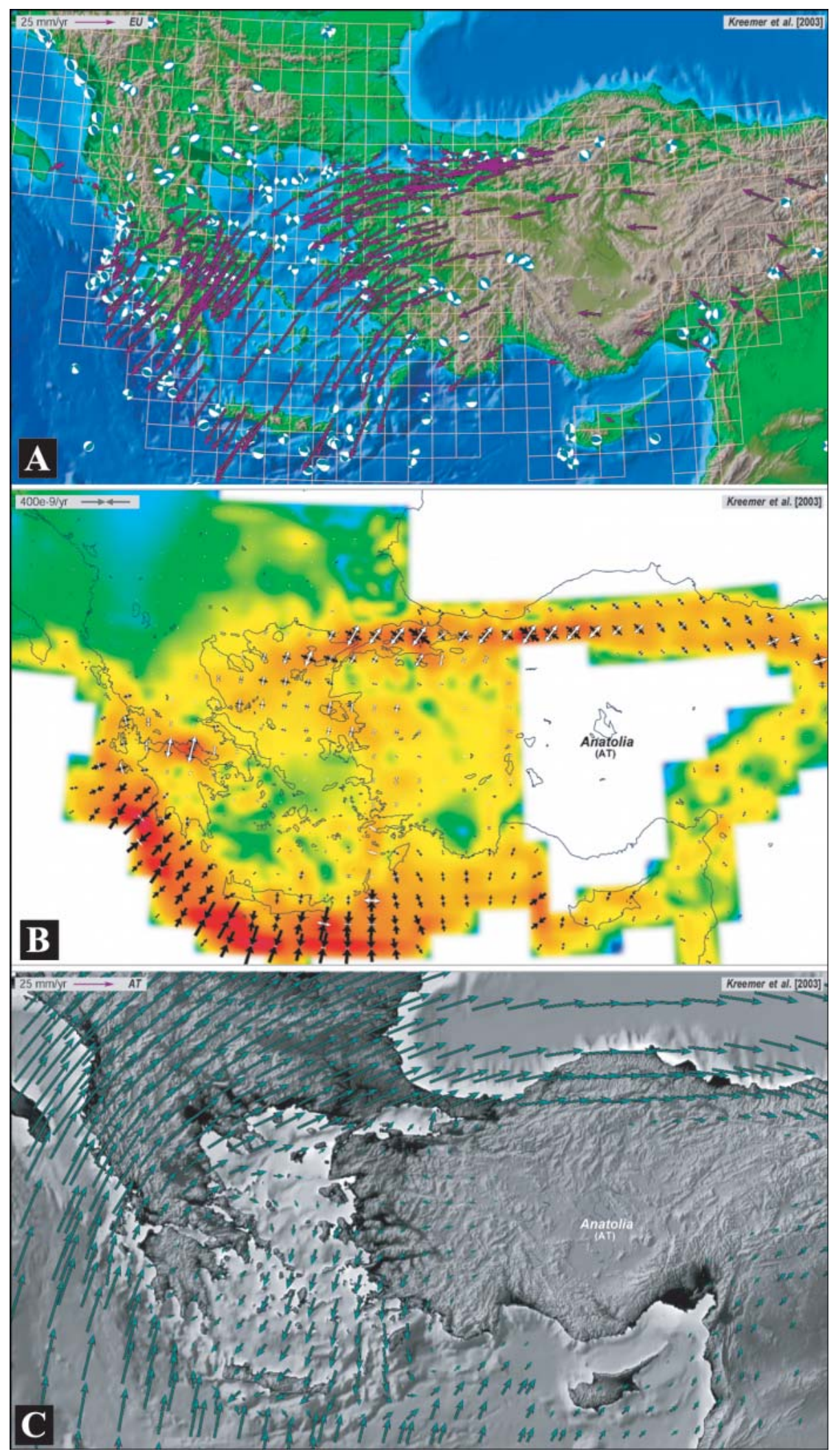

Fig. 2. Three examples of maps that are created with the Jules Verne Voyager (http://jules. unavco.org/Voyager/ILP_GSRM) for the Aegean-Turkey area. (a) Focal mechanisms from the Harvard Centroid Moment Tensor (CMT) catalog are shown together with GPS velocities (purple arrows) relative to the model Eurasian reference frame. Also shown are outlines of the model grid cells. (b) Contour plot of the interpolated second invariant of model strain rate tensor superimposed with model principal strain rate axes (extensional in white, compressional in black). (c) Interpolated model velocities (green arrows) relative to the model Anatolia reference frame. 
Eos, Vol. 86, No. 41, 11 October 2005

\section{Scientific Results to Date}

The GSRM present-day plate motions [Kreemer et al., 2003] have been compared with the NUVEL-1A model, which is the existing plate kinematic model that was derived from oceanic ridge spreading rates, transform fault azimuths, and earthquake slip vectors [DeMets et al., 1994]. Generally, the geodetically-derived plate motions are in good agreement with NUVEL-1A.

However, some notable differences exist particularly in rate (see also Sella et al. [2002] for a discussion).Africa (now generally regarded to consist of two separate plates, Nubia in the west and Somalia in the east), India, and Arabia for example, all move significantly slower with respect to Eurasia, compared with the NUVEL1A estimates. The Caribbean Plate, on the other hand, moves considerably faster than previously thought with respect to the Americas.

The examples cited above, and most of the discrepancies between GSRM and NUVEL$1 \mathrm{~A}$, are generally believed to be the result of data incompleteness in the NUVEL-1A model. The only plate that has a geodetic velocity magnitude different from the three-millionyear average, that is arguably a real change in plate motion rather than a discrepancy due to data incompleteness, is the Nazca Plate.That plate is slower relative to the South American Plate by approximately 15-19\% [e.g., Norabuena et al., 1999].

A reference frame often used in plate kinematic and dynamic studies is the no-netrotation (NNR) frame. This is a kinematicallydefined reference frame in which the global integral of the cross product of the velocity with the radial vector is zero. The proper determination of this reference frame requires knowledge of the horizontal surface velocity field at all points on the Earth. Unlike previous models, which generally used NUVEL-1A, the GSRM model correctly determines the NNR frame by using accurate surface velocities at all points on the Earth, including the diffuse plate boundary zones [Kreemer and Holt, 2001; Kreemer et al., 2003]. One important application of the NNR model is in the definition of the International Terrestrial Reference Frame (ITRF) [Altamimi et al., 2003], used as the standard geodetic reference frame worldwide.

There is enormous potential for the results of the GSRM project to be used in a whole range of studies, particularly in seismotectonics, seismic hazard analysis, and lithospheric dynamics.

Kreemer et al. [2002] compared the tectonic moment rates predicted by the GSRM with seismicity rates (i.e., the number of shallow events within a certain region with $M_{w}$ 5.8). They confirmed that there is a strong correlation between seismicity rates and the tectonic moment rates for both subduction zones and for zones of continental deformation. Such a correlation may hold promise for quantification of long-term moment rates, and hence seismic hazard, particularly within slowly deforming regions [Kagan,1999].

In another ongoing study, the apparent positive correlations between geothermal activity and strain rates in the Great Basin of the western United States are being investigated
[Blewitt et al.,2003]. In particular, there is a positive correlation of geothermal activity and transtensional-type strain rates (mixed strikeslip and normal faulting).

The GSRM is also being used to quantify net rates of shortening and extension (dilatation rates) within continental lithosphere. Results from the present-day deformation field on Earth show that the net rate of dilatation within continental lithosphere is negative $\left(-0.18 \pm 0.02 \mathrm{~km}^{2} / \mathrm{yr}\right)$ [Hahn et al.,2004]. That is, ocean basins are increasing in area at the expense of tectonic reduction of area within the continents.

This reduction in continental area must be balanced by sedimentation on oceanic lithosphere if continental area is to remain constant over time. If tectonically-induced areal reduction in continental lithosphere is a steady state feature within the Wilson Cycle (the period involving supercontinent break-up and formation through continent-continent collision), then such sedimentation of eroded continental mass onto oceanic crust is at least as important as island arc accretion in maintaining constant continental area [Hahn et al.,2004].

\section{Future Plans for GSRM}

GSRM results will benefit from the growing deployment of GPS velocity measurements, obtained through either campaign-style or permanent networks, such as the Plate Boundary Observatory of the EarthScope Project. Indeed, GSRM project results will be frequently updated as GPS velocities become available.

For the future, using the GSRM online interface at UNAVCO, there are plans to incorporate the ability for a user to contribute new data to the model and calculate results. It is also the intention of the GSRM project to incorporate strain rate models and methods from other investigators [e.g., Bird, 2003].

In addition to the increase in GPS data, other data sources need to be considered. This is particularly necessary to cover areas without geodetic velocity estimates or with very low strain rates, and to evaluate the appropriateness of the geodetic strain rates over longer time scales. A globally complete archive of active fault slip rate measurements within the continents, together with seafloor magnetic and bathymetry data, would enable the determination of a geologically defined GSRM.The partly completed ILP project-II-2 World Map of Major Active Faults-will be particularly important for such a model.

Ultimately, the GSRM will be able to include time dependence and vertical components of strain rate. New frontiers in continuous mapping of surface deformations using interferometric synthetic aperture radar (InSAR) and lidar technology point to the possibility of realizing continuous four-dimensional strain rate measurements and models of the Earth's surface in near real- time.

These kinematic models could ultimately be linked to dynamic models that incorporate forcing effects at all scales. This would take into account the individual contributions of crustal tectonic loading, crust and mantle flow, and hy- drologic, atmospheric, and ocean forcing to the observed strain rates

\section{Acknowledgments}

We thank the GSRM Steering Committee (D. Argus, J. Beavan, R. Bennett, P. Bird,

E. Calais, A.Caporali, J.-F.Cretaux, J. Freymueller, A. Friedrich, S. Goes, R. Gordon, R. Hartog, K. Heki, D. Jackson,Y. Kagan, M. Nyst,Y. Rong, R. Sabadini, Z.-K.Shen,W.Spakman,S.Stein, and S.Wdowinski) for their valuable input. We thank the International Lithosphere Project, and its directors, for support on ILP project II-8. We also acknowledge NASA, NSF, and UNAVCO for support on the research and development that has gone into making the GSRM.

\section{References}

Altamimi, Z., P. Sillard, and C. Boucher (2003), The impact of a no-net-rotation condition on ITRF2000, Geophys. Res. Lett., 30(2), 1064, doi:10.1029/ 2002GL016279.

Bird, P. (2003), An updated digital model of plate boundaries, Geochem. Geophys. Geosyst., 4(3), 1027, doi:10.1029/2001GC000252.

Blewitt, G., M. F. Coolbaugh, D. L. Sawatzky,W. Holt, J. L. Davis, and R.A. Bennett (2003), Targeting of potential geothermal resources in the Great Basin from regional to basin-scale relationships between geodetic strain and geological structures, Trans. Geothermal Resour. Counc., 27,3-7.

Davies, P., and G. Blewitt (2000), Methodology for global geodetic time series estimation: A new tool for geodynamics, J. Geophys. Res., 105(B5), 11,083-11,100.

DeMets, C., R. G. Gordon, D. F.Argus, and S. Stein (1994), Effect of recent revisions to the geomagnetic reversal timescale on estimates of current plate motions, Geophys. Res. Lett., 21(20), 2191-2194.

Hahn, B. C., C. Kreemer,W. E. Holt, P.G. Silver, and A. J. Haines (2004), Building on current space-based geodesy to infer long-term tectonic reduction in continental area, Eos Trans. AGU, 85(47), Fall Meet. Suppl.,Abstract G41A-08.

Kagan,Y.Y. (1999), Universality of the seismic moment-frequency relation, Pure Appl. Geophys., 155, 537-573.

Kreemer, C., and W.E. Holt (2001), A no-net-rotation model of present-day surface motions, Geophys. Res. Lett., 28(23), 4407-4410.

Kreemer, C., W.E. Holt, and A. J. Haines (2002), The global moment rate distribution within plate boundary zones, in Plate Boundary Zones, Geodyn. Ser., vol. 30, edited by S. Stein and J.T. Freymueller, pp. 173-190, AGU, Washington, D. C.

Kreemer, C.,W. E. Holt, and A. J. Haines (2003), An integrated global model of present-day plate motions and plate boundary deformation, Geophys. J. Int., 154, 8-34.

Norabuena, E. O., T.H. Dixon, S. Stein, and C. G.A. Harrison (1999), Decelerating Nazca-South America and Nazca-Pacific plate motions, Geophys. Res Lett., 26(22), 3405-3408.

Sella, G. F., T. H. Dixon, and A. Mao (2002), REVEL: A model for Recent plate velocities from space geodesy, J. Geophys. Res., 107(B4), 2081, doi:10.1029/2000JB000033.

\section{Author Information}

William E. Holt, State University of New York at Stony Brook; Corné Kreemer, Nevada Bureau of Mines and Geology, University of Nevada, Reno; A. John Haines, University of Cambridge, U.K.; Lou Estey and Chuck Meertens, UNAVCO, Boulder, Colo.; Geoffrey Blewitt, Nevada Bureau of Mines and Geology, University of Nevada, Reno; and David Lavallée, School of Civil Engineering and Geosciences, University of Newcastle upon Tyne, U.K.

For additional information, contact W.E. Holt; E-mail:wholt@mantle.geo.sunysb.edu. 